\title{
POLICY COMPLEMENTARITY AND CONFLICT IN REGIONALLY DISAGGREGATED MACROECONOMIC MODELS: AN EXAMPLE FROM THE BRAZILIAN EXPERIENCE
}

Richard $P$. liarber $J r$.

Texas Tech University - USA

\section{ABS TRACT}

In this paper, the interrelated nature of the growth and regional inequality goals is examined. Then we analise the interdepen dencies between simultaneous pursuit of national growth and regio nal equality, and the possible complementarity orconflicting results of exogenous events and macroeconomic policies toward those ends. These interdependecies are ilustrated through the use of a simple two-region aggregated demand model. As an application of the previous analysis a case study of Brazil's experience during the 1960's and 1970's is presented.

\section{RESUMO}

Neste trabalho examinamos a natureza interdependente entre as netas de crescimento econōmico e desigualdade regional. Estudamos a possivel complementaridade ou conflito de eventos exōgenos e de políticas macroeconômicas que busquem tais metas. Nesse sentido, ilustramos a discussão com un modelo simples de demanda agregada para duas regiōes. Completamos a anālise com um estudo do caso refer-ente à experiência brasileira dos anos de 60 e 70 . 


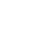


I. INTRODUCTION

National policy goals throughout the world typically include the promotion of economic growth and the reduction of domestic regional inequalities. Even though neoclassical regional growth models indicate that regional per capita incomes will converge in the long run due to factor migration and that equilibrium growth rates are basically limited by population growth rates, many govern ments are either doubtful of these conclusions or unwilling (or unable) to wait for the long-run convergence of regional incomes and the achievement of equilibrium growth. As a result policies are adopted to both promote national growth and to alleviate the regio nal inequities which exist. Unfortunately, the economic models used to analyze these problems and to develop policies to correct them often neglect the basic interrelationships between the national and regional policies and circumstances. This neglect often leads to the adoption of policies which are conflicting, rather than comple mentary, with respect to the policy goals.

In this paper, the interrelated nature of the growth and regional in equality goals is examined in section II. Then, the inter dependencies between simultaneous pursuit of national growth and regional equality, and the possible complementary or conflicting results of exogenous events and macroeconomic policies toward those ends axe analyzed in section III. These interdependencies are discussed and illustrated through the use of a simple two-region aggregate demand model. As an application of the previous analysis, a case study of Brazil's experience during the 1960's and 1970's is presented in section IV.

I I. NATIONAL GRO!NTH AND REGIONAL INEQUALITY:

THE EA ASIC INTERDEPENDENCY

To isllustrate the relationship between national growth regional inequality a general case of $\underline{n}$ regions could be considered; ho wever, to simplify the exposition, assume two regions ( $A$ and $B$ ) 
where region $A$ is poorer than region $B$. To further simplify the argument, assume either that the population growth rates for both regions and the nation are the same, or that total rather than per capita income is the appropriate measure for judging regional inequality and national growthl. In addition assume that the policy goals of the government are to promote high national growth rates or, alternatively, large proportional changes in national income and to reduce the inequality between the two regions ${ }^{2}$.

To formally develop the interdependency between these two goals, define the following variables:

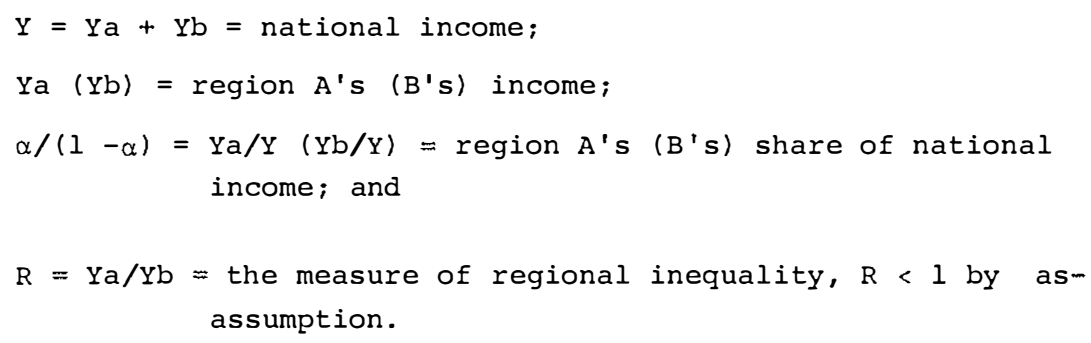

Letting a circumflex over a variable indicate the proportional chan ge or trowth rate of a variable, the proportional change in national income $(Y)$ and in the measure of regional inequality ( $R$ ) are

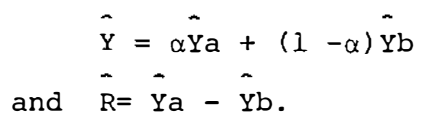

Verbally, these relationships show that the national growth rate is a weighted average of the regional growth rates, while chan ges in the measure of regional inequality are determined by the difference between the growth rates. It is now possible to identify how conflicts between the two policy objectives may arise. Reduction of regional inequality requires that $\mathrm{R}$ move toward $\mathrm{J}$, im plying that $\mathrm{Qa}>\mathrm{Qb}$ is necessary for a reduction of regional inequality ${ }^{3}$. A high national growth rate is most easily attained, however, by greater growth in region B since the weight on region B's growth rate $(1-\alpha)$ is greater than the weight on region A's growth 
rate $(\alpha)$. Thus, there is a trade-off between the ease of achieving any given national growth rate and the reduction of regional inequality; however, it is still clearly possible to satisfy both goals.

\section{I . POLICY CONFLICT OR COMPLEMENTARITY}

Conceptually it is clear how different policies can be in conflict or be complementary with respect to achieving the goals of stimulating national growth and reducing regional inequality. To generate the largest effects on national growth for a given effort, policies should be biased towards region B. Such a policy bias, ho wever, woulc most likely lead to a worsening of regional inequality, unless the cross-regional effects from B to $A$ are very strong. In other words, the curve relating the possible combinations of national growth and improvements in regional equity may have either a positive or negative slope depending upon the regional economies' structures and the economics policy mix chosen.

To formally develop this idea a basic model of how policy mea sures affect the levels of regional income is needed. To satisfy this need and to provide the basic theoretical underpinnings for the analysis of Brazil's policies presented in the next section, a two region aggregate demand model is developed and analyzed in this section. The model is composed of four equations for each region: an aggregate regional expenditures function; an interregional import function; an interregional trade equilibrium conditium; and a regional income equilibrium condition. Aggregate regional expenditures (E) in each region are composed of consumption, investment and government expenditures plus net foreign exports; these expenditures are a function of both regions' income ( $\mathrm{Ya}, \mathrm{Yb})$, region specific exogenous and policy variables ( $z i k ; i=a, b ; k=1,2, \ldots, m)$, and national exogenous and policy variables $(\mathrm{zh} ; \mathrm{h}=1,2, \ldots, \mathrm{h})$. Interregional imports (Mi; $i=a, b)$ are a function of each region's in. come. The interregional trade equilibrium conditions state that each region's regional exports $(x i ; i=a, b)$ must equal the regional 
imports of the other region; while the regional income equilibrium conditions simply state that each region's income must be equal to the sum of that region's aggregate regional expenditures and net-interregional exports. Thus, the model's eight structural equa tions are as follows 4 :

Aggregate Regional Expenditure Functions:

$$
\begin{aligned}
& E a=E a(Y a, Y b, Z a l, Z a 2, \ldots, Z a m, Z l, Z 2, \ldots, Z n) \quad(3 . a) \\
& E b=E b(Y b, Y a, Z b l, Z b 2, \ldots, Z b m, Z l, Z 2, \ldots, Z n) \quad(3 . b) \\
& E i_{1}=\partial E i / \partial Y i>0 ; E i_{2}=\partial E i / \partial Y j>0 ; E i_{1}+E j_{2}<1 ; i \neq j ; \\
& E i_{2+k}=\partial E i / \partial Z i k \frac{\geq}{<} 0 \\
& E i_{2+m+h}=\partial E i / \partial Z h \geq 0
\end{aligned}
$$

Interregional Import Functions:

$$
\begin{aligned}
& M a=M a(Y a) \\
& M b=M b(Y b) \\
& M i^{\prime}=d M i / d Y i>0
\end{aligned}
$$

Interregional Trade Equilibrium Conditions:

$$
\begin{aligned}
& \mathrm{Xa}=\mathrm{Mb} \\
& \mathrm{Xb}=\mathrm{Ma}
\end{aligned}
$$

Regional Income Equilibrium Conditions:

$$
\begin{aligned}
& Y a=E a+X a-M a \\
& Y b=E b+X b-M b
\end{aligned}
$$

Substitution of equations 3,4 , and 5 into equations 6 and solving for the proportional change (growth rate) of the regional incomes $(9 \mathrm{a}, \mathrm{Pb})$ in terms of the proportional chances of the exogenous and policy variables ( $2 \mathrm{ak}, 2 \mathrm{bk}, 2 \mathrm{~h}$ ) yields: 


$$
\begin{aligned}
& \mathrm{Ya}=(\mathrm{F} / \mathrm{D}) \underset{\mathrm{k}=1}{\mathrm{~m}} \phi \mathrm{k} \quad \mathrm{Ea}_{2+\mathrm{k}} \hat{\mathrm{Z} a} \mathrm{k}+(\mathrm{I} / \mathrm{RD}) \sum_{\mathrm{k}=1}^{\mathrm{m}} \psi \mathrm{k} \mathrm{Eb}_{2+\mathrm{k}} \hat{\mathrm{z} b \mathrm{k}} \\
& +-\frac{l+R}{R D}-\sum_{h=1}^{\mathrm{n}}\left\{\mathrm{FEa}_{2+\mathrm{m}+\mathrm{h}}+\mathrm{IEb}_{2+\mathrm{m}+\mathrm{h}}\right\} \text { oh } \hat{\mathrm{z}} \mathrm{h}
\end{aligned}
$$

and $\hat{Y} b=(R K / D) \underset{k=1}{\sum_{k}^{m}} \Phi k \quad E a_{2+k} \hat{z} a k+(H / D) \underset{k=1}{\sum_{k=1}^{m}} \Psi k E_{2+k} \hat{z} b k$

$$
+\frac{l+R}{D} \sum_{h=1}^{n}\left\{K_{E a_{2+m+h}}+\mathrm{IIEb_{2+m+h }}\right\} \theta \mathrm{h} \hat{\mathrm{z} h}
$$

where

$$
\begin{array}{ll}
\mathrm{D}=\mathrm{HF}-\mathrm{IK}>0 & \mathrm{~K}=\mathrm{Eb}_{2}+\mathrm{Ma}>0 \\
\mathrm{H}=1-\mathrm{Ea}_{1}+\mathrm{Ma}^{\prime}>0 & \phi \mathrm{k}=\mathrm{Zak} / \mathrm{Ya} \\
\mathrm{I}=\mathrm{Ea} \mathrm{a}_{2}+\mathrm{Mb} \mathrm{b}^{\prime}>0 & \Psi \mathrm{k}=\mathrm{Zbk} / \mathrm{Yb} \\
\mathrm{F}=1-\mathrm{Eb}_{\mathrm{I}}+\mathrm{Mb} \mathrm{b}^{\prime}>0 & \theta \mathrm{h}=\mathrm{Zh} / \mathrm{Y} .
\end{array}
$$

Substitution of equations 7 into equations 1 and 2 results in the following expressions for the national growth rate and the per centage change in regional inequality in terms of the exogenous and policy variables:

$$
\begin{aligned}
& \hat{\mathrm{y}}=\frac{\mathrm{R}}{\mathrm{l}+\mathrm{R}} \frac{\mathrm{F}+\mathrm{K}}{\mathrm{D}} \sum_{\mathrm{k}=1}^{\mathrm{m}} \Phi_{\mathrm{k}} \mathrm{Ea}_{2+\mathrm{k}} \hat{\mathrm{Z}} \mathrm{ak}+\frac{\mathrm{I}}{1+\mathrm{R}} \frac{\mathrm{I}+\mathrm{H}}{\mathrm{D}} \sum_{\mathrm{k}=1}^{\mathrm{m}} \psi \mathrm{k} \\
& \mathrm{Eb}_{2+\mathrm{k}} \hat{\mathrm{Z}} \mathrm{bk}+{ }_{\mathrm{h}=}^{\mathrm{n}=1}\left\{(\mathrm{~F}+\mathrm{K}) \mathrm{Ea}_{2+\mathrm{m}+\mathrm{h}}+(\mathrm{I}+\mathrm{H}) \mathrm{Eb}_{2+\mathrm{m}+\mathrm{h}}\right\} \frac{\Theta \mathrm{h}}{\mathrm{D}} \hat{\mathrm{Z}} \mathrm{h}
\end{aligned}
$$

and

$$
\begin{aligned}
\tilde{R}= & \frac{F-R K}{D} \sum_{k=1}^{m} \phi k E a_{2+k} \hat{z} a k+\frac{I-R H}{R D} \sum_{k=1}^{m} \psi k E b_{2+k} \hat{z} b k \\
& +\frac{1+R}{R D} \sum_{h=1}^{n}\left\{(F-R K) E a_{2+m+h}+(I-R H) E b_{2+m+h}\right\} \Theta h \hat{z} h .
\end{aligned}
$$


Equations 8 and 9 form the basis for the analysis of whether a given policy or exogenous change generates effects which are com plementary or in conflict with respect. to the policy goals. The coefficients of the exogenous and policy variables in these equations show the contribution of a one percent change in these varia bles to the national growth rate and the proportional change of regional inequality, respectively. Assume $\hat{z} a k, \hat{z} b k$ and $\hat{z} h$ all have values which contribute positively to national growth. Division of the coefficient of each independent variable in equation 9 by the corresponding coefficient in equation 8 gives the following expressions for the "Complementarity-Conflict Ratio" for each set of exogenous/policy variables:

$$
\begin{aligned}
& C C R a=\frac{l+R}{R} \frac{F-R K}{F+K} \text { for the Region A especific variables; } \\
& C C R b=\frac{1+R}{R} \frac{I-R H}{I+H} \text { for the Region } B \text { specific variables; and } \\
& C C R h=h(C C R a)+(1-\Omega h)(C C R b) \text { for the hth national variable; }
\end{aligned}
$$
where

$$
\Omega h=\frac{F+K}{(F+K)+(I+H) \omega h}
$$

and

$$
w h=\left(E b_{2+m+h}\right) /\left(\mathrm{Ea}_{2+m+h}\right)
$$

If these Complementarity-Conflict Ratios have the value $\underline{x}$, then a change producing a one percent increase in national income would also produce an $x \%$ change in regional inequality. The sign of these ratios indicates whether a given exogenous or policy change produces complementary or conflicting effects with regard to the stated policy goals, while the size of the ratios indicates the intensity of their effects. If the ratio is negative, then chan ges in the respective policy variables produce conflicting effects on national growth and regional inequality, while a positive value for the ratio indicates complementary effects. The larger the abso lute value of the ratio, the greater the effect (either positive or negative) on regional insquality for a given change in the national growth rate. 
Even though these Complementarity-Conflict Ratios can be used to identify whether individual independent variable changes genera te complementary or conflicting effects with respect to the poli cy goals, they are not sufficient for the analysis of the complete policy vector. To determine if a given policy vector generates complementary or conflicting effects the following Total or Aggregate Complementarity-Conflict Ratio (CCRT) must be used ${ }^{5}$ :

$$
\mathrm{CCRT}=\frac{\Delta \mathrm{a}}{\Delta} \mathrm{CCRa}+\frac{\Delta \mathrm{b}}{\Delta} \mathrm{CCRb}+\frac{\Delta \mathrm{N}}{\Delta} \underset{\mathrm{h}=1}{\mathrm{n}} \mathrm{x}^{\mathrm{h}} \mathrm{CCRh}
$$

where

$$
\begin{aligned}
\Delta & =\bar{Y}=\text { equation } 8 ; \\
\Delta a & =\left.\bar{Y}\right|_{\hat{Z} a}=\frac{R}{1++R} \frac{F+K}{D} \sum_{k=1}^{m} \Phi k \mathrm{Ea}_{2+k} \text { zak } \\
& =\begin{array}{l}
\text { the percentage change in national income due to region } A^{\prime} s \\
\text { policy changes; }
\end{array}
\end{aligned}
$$

$$
\begin{aligned}
\Delta \mathrm{b} & =\left.\hat{\mathrm{Y}}\right|_{\hat{\mathrm{Z}} \mathrm{b}}=\frac{\mathrm{I}}{\mathrm{I}+\mathrm{R}} \frac{\mathrm{I}+\mathrm{H}}{\mathrm{D}} \sum_{\mathrm{k}=\mathrm{l}}^{\mathrm{m}} \Psi \mathrm{k} \mathrm{Eb}_{2+\mathrm{k}} \hat{\mathrm{Z} b \mathrm{~b}} \\
& =\begin{array}{l}
\text { the percentage change in national income due to region } \mathrm{B} \text { 's } \\
\text { policy changes; }
\end{array}
\end{aligned}
$$

$$
\Delta N=\left.\bar{Y}\right|_{\hat{z}}=\sum_{h=1}^{n}\left\{(F+K) E a_{2+m+h}+(I+H) E b_{2+m+h}\right\} \frac{\theta h}{D} \hat{z} h
$$

$=$ the percentage change in national income due to national policy changes;

$$
\begin{aligned}
\chi^{h=} & \left.\hat{\mathrm{y}}\right|_{\hat{\mathrm{z} h}} / \Delta \mathrm{N}=\left(\left\{(F+\mathrm{K}) \mathrm{Ea} \mathrm{a}_{2+\mathrm{m}+\mathrm{h}}+(\mathrm{I}+\mathrm{H}) \mathrm{Eb}_{2+\mathrm{m}+\mathrm{h}}\right\}(\mathrm{Oh} / \mathrm{D}) \hat{\mathrm{z} h}\right) / \Delta \mathrm{N} \\
= & \text { national policy variable } \mathrm{h} \text { 's relative contribution to } \\
& \text { the total percentage change in national income due to na } \\
& \text { tional policy changes; }
\end{aligned}
$$

$1=\frac{\Delta a}{\Delta}+\frac{\Delta b}{\Delta}+\frac{\Delta N}{\Delta} ;$ and

$$
\sum_{h=1}^{n} x^{h}=1
$$


The Total or Aggregate Complementarity-Conflict Ratio is a weighted average of the regional and national policy complementari ty-conflict ratios where the weights used are the relative contri butions of each set of policies to the total percentage change in national income, and is interpreted in the same manner as the indi vidual Complementarity-Conflict Ratios.

IV. POLICY CONFLICT AND COMPLEMENTARITY: THE BRAZILIAN EXPERIENCE

The ideas developed in the last section regarding policy conflict or complementarity are applied to the case of Brazil in this section. As is well documented in the literature dealing with Brazil's economic development, Brazil has had severe regional imbalan ces and a generally successful growth experience over the past fifteen years ${ }^{6}$. It has also been recognized that many of the policies adopted to promote national growth may have had adverse effec ts on the regional problem 7 .

The model used to evaluate the effects of Brazil's economic policies on growth and regional inequality is analogous to the model presented in the last section ${ }^{8}$. Region $A$ is the Brazilian Nort heast and Region $B$ is the rest-of-Brazil. The structural equations underlying the regional expenditure functions follow the standard Keynesian formulations except for the inclusion of Brazil's export and fiscal incentive systems ${ }^{9}$. Table 1 lists the model's exogenous and policy vaxiables, while Table 2 presents the estimated parameter values.

Our analysis divides the 1965 to 1980 period into five subperiods which are determined by the availability of consistent data, Brazil's economic performance, and an attempt to use time periods of equal length. Consistent macroeconomic data are available from 1965 through 1980 (data for certain variables are not available after 1977). With the exception of two subperiods, three year in- 
tervals have been used. The 1965-67 subperiod is the latter part of the military stabilization period marked by relatively slow eco nomic growth. The four-year subperiod of 1970-74 is the latter half of the high growth period commonly known as the the "Brazilian Miracle".

Table 3 presents the values of the Complementarity-Conflict tios for each of the five subperiods. The classification of the exogenous and policy variables by whether they generate complementa ry or conflicting effects and by the relative intensity of their effects (Table 4) shows that there are four variables which genera ted complementary effects in all time periods $(\mathrm{Na}, \zeta, \lambda, W$ ), three variables which generated conflicting effects in all time periods $(\mathrm{Nb}, e, \gamma)$, and three variables whose effects switch from being conflicting to complementary as regional inequality worsened in the late 1960's and 1970's $(\varepsilon, Y F, G)$. Further, the ranking of the intensities of the independent variables' effects from "most complementary" (highest CCR) to "most conflicting" (lowest CCR) remains constant throughout the time period.

The effects of the policy vector are analyzed in TAble 5. Rather than discuss each independent rariable, their effects have been grouped toghether according to their "type" (Exogenous, Exoge nous/Policy, of Policy) as identified in Table 2. Examination of the CCRT values shows that the net effect of the policy vector was complementary in three of the five subperiods (1965-67, 1970-74, and 1974-77), while it was conflicting in two subperiods (1967-70 and 1977-80). Except for the 1965-67 period, however, the intensity of both the complementary and conflicting effects have been relati. vely low as indicated by the small absolute CCRT values. From 1967 through 1980, the largest absolute CCRT is 0.612 which tells us that a 0.68 change in the ratio. of Region A's income to Region B's income resulted for each 1.08 of induced growth.

Using equation 8, the contribution of each group of indepen dent variables to Brazil's growth was calculated. The results show that throughout the fifteen years being examined the major impetus to growth came from the exogenous variable (U.S. income) which accounts for at least ninety percent $(90 \%)$ of the induced growth. On 
the other hand the growth effects of the policy variables, when positive, were responsible for a relatively small portion of the total growthl0. From 1967 to 1970 the policy variables accounted for 16.48 of Brazil's growth, while the changes in U.S. income accounted for 97.58 of that growth and the mixed policy/exogenous va riables made a negative contribution of 13.98. During the 1977-80 subperiod U.S. income was responsible for almost 923 of the induced growth while the policy variables accounted for approximately $8 \%$ of this growth.

The independent variables's relative contributions to the Aggregate Complementarity-Conflict Ratios have been the opposite of their relative contributions to national growth. The policy varia bles account for the greatest portion of the observed CCRT values. Excepting the 1974-77 subperiod when the policy variables account for only 618 of the CCRT value, these variables have been responsible for more than $82 \%$ of the observed CCRT values.

Since the policy variables have had a relatively small effect on national growth, it is reasonable to ask if they have had favorable impacts on regional inequality. As is clear from the last portion of Table 5, in the periods when these policies were contra ctionary with respect to growth (1965-67, 1970-74, and 1974-77), they improved the regional distribution; the opposite is true, however, for the periods of net expansionary policy (1967-70 and 1977 -80). During the 1965-67 stabilization period, the policy variables acted to offset the negative influence on regional distribu tion of the exogenous variables, but had the same effects on this distribuition as the exogenous variables from 1968 through 1977. After 1977 the policy variables' effects again ran counter to those of the exogenous variables, thus acting to worsen regional inequality.

The result that Brazil's domestic policies have made relatively small contributions to her induced growth, while the contribu tion of foreigner income has been large, may be viewed by some as surprising. The information in Table 6 provides the basis for explaining this result. The top half of Table 6 shows the percentage change of the exogenous and policy variables, while the bottom half 
gives the value of their coefficients in equation 8 . Together, the se items determine the variables's absolute contribution to induced growth.

The principal reason for the large contribution of foreign in come (YF) to Brazil's growth is the size of its growth rate coefficient, ranging from 625 in the 1965-67 period to 335 in the 1977 -80 period. These coefficients are at least six times, and up to fourteen times, as large as the maximum growth rate coefficient for the policy variables. Thus, despite the relatively small percentage changes in foreign income, its contribution to Brazil's growth has been substancial.

The policy variables's relatively small contribution to indu ced growth comes from two sources. First, their growth rate coeffi cients are relatively small. Second, and most importantly, the policies have been contradictory in terms of their effects on growth. As is clear from Table 6, the devaluations of the nominal exchange rate under the governments' cravling-peg policy resulted in a reva luation of the real exchange rate in the 1965-67, 1970-74, and 1974 -77 periods. Given the large, positive values of the real exchange rate's growth rate coefficient, these revaluations generated substantial contractionary effects, offsetting the expansionary nature of the other policies.

The conclusion to be drawn from the above analysis is that the Brazilian authorities have had very little success at coordina ting their policy $\mathrm{mix}$ to both stimulate growth and improve the regional distribution of the national product. The major contributing factor to Brazilian growth over these fifteen years has been the favorable growth performance of the United States which is totally outside the control of Brazil's macro-policymakers. For the subperiods when Brazil's macro-policy has had net stimulative effects on the economy, it has had negative effects on regional distribution, while the reverse has been true for the periods when there were net contractionary effects from the macro-policies. Thus, at least for this fifteen year period, the slope of the curve showing the possible combinations of national growth and regional distribu tion has been negative. 
Table 1

EXOGENOUS AND POLICY VARIABLES FOR THE BRAZILIAN MODEL

\begin{tabular}{|c|c|c|}
\hline VARIABLE & $\begin{array}{l}\text { VARI ABLE } \\
\text { INDEX }\end{array}$ & TYPE OF VARIABLE* \\
\hline $\begin{array}{l}\text { Northeast's Aggregate Incen- } \\
\text { tive Investment Multiplier } \\
(\mathrm{Na})\end{array}$ & $\mathrm{Za} 1$ & Policy/Exogenous \\
\hline $\begin{array}{l}\text { Rest-of-Brazil's Aggregate } \\
\text { Incentive Investment } \\
\text { Multiplier ( } \mathrm{Nb})\end{array}$ & $\mathrm{Zb} 1$ & Policy/Exogenous \\
\hline Foreign Income (YF) & 21 & Exogenous \\
\hline Exchange Rate (e) & $\mathrm{Z2}$ & Policy \\
\hline Export Subsidy Rate $(\varepsilon)$ & 23 & Policy \\
\hline Government Expenditures (G) & 24 & Policy \\
\hline $\begin{array}{l}\text { Northeast's Share of Govern- } \\
\text { ment Expenditures }(\gamma)\end{array}$ & 25 & Policy \\
\hline $\begin{array}{l}\text { Private to Incentive-Induced } \\
\text { Investment Ratio }(\lambda)\end{array}$ & 26 & Policy/Exogenous \\
\hline $\begin{array}{l}\text { Northeast's Share of Disbur- } \\
\text { sed Fiscal Incentive Funds } \\
(\zeta)\end{array}$ & 27 & Policy/Exogenous \\
\hline $\begin{array}{l}\text { Fraction of Incentive Funds } \\
\text { Retained per Time Period (W) }\end{array}$ & 28 & Policy/Exogenous \\
\hline
\end{tabular}

(*) The variables labelled "Policy/Exogenous" are neither purely policy nor purely exogenous variables sinc' they are determined both by policy actions and by other exogenous forces, hence the combined classification. 
Table 2

PARAMETER ESTIMATES FOR THE BRAZILIAN MODEL*+

\begin{tabular}{|c|c|c|c|}
\hline PARAMETER & $\begin{array}{l}\text { DERIVATIVE WITH } \\
\text { RESPECT TO: }\end{array}$ & $\begin{array}{l}\text { REGION A } \\
\text { (NORTHEAST) }\end{array}$ & $\begin{array}{c}\text { REGION B } \\
(\text { REST-OF-BRAZIL) }\end{array}$ \\
\hline $\mathrm{Ei}_{1}$ & $\mathrm{Yi}$ & 0.7490 & 0.7991 \\
\hline $\mathrm{Ei}_{2}$ & $\mathrm{Y}_{\mathrm{j}}$ & 0.640 & 0.0681 \\
\hline $\mathrm{Ei}_{3} / \mathrm{Z}$ & $\mathrm{Ni}$ & 10.0443 & 10.9557 \\
\hline $\mathrm{Ei}_{4}$ & YF & 1751.0 & 13310.0 \\
\hline $\mathrm{Ei}_{5}$ & e & -667500.0 & 1018100.0 \\
\hline $\mathrm{Ei}_{6}$ & $\varepsilon$ & 63374.0 & 423645.0 \\
\hline $\mathrm{Ei}_{7}$ & G & 0.05 & 0.95 \\
\hline $\mathrm{Ei}_{8} / \mathrm{G}$ & $\gamma$ & 1.0 & -1.0 \\
\hline $\mathrm{Ei}_{9} / \mathrm{z}$ & $\lambda$ & 0.2343 & 0.4051 \\
\hline $\mathrm{Ei}_{10} / 2$ & $\zeta$ & 10.2879 & 16.3065 \\
\hline $\mathrm{Ei}_{11} /(t-1)$ & $W$ & 4.9207 & 8.5071 \\
\hline $\mathrm{Mi}{ }^{\prime}$ & $\mathrm{Yi}$ & 0.5680 & 0.0065 \\
\hline
\end{tabular}

(*) Average values. Foreign (United States) income was measured in billions of dollars, while Brazil's aggregate values were measured in millions of cruzeiros. For converting nominal to real terms, the implicit GNP deflators with 1970 as the base year were used.

+ These estimates are based upon annual data and were found using the Three -Stage Least Squares estimation procedure.

Source: Harber (1982a). 
Table 3

COMPLEMENTARITY-CONFLICT RATIOS FOR THE BRAZILIAN MOOEL

\begin{tabular}{|c|c|c|c|c|c|}
\hline & \multicolumn{5}{|c|}{ TIME PERIODS } \\
\hline & $1965-67$ & $1967-70$ & $1970-74$ & $1974-77$ & $1977-80$ \\
\hline CCRa (Na) & 1.640 & 1.520 & 1.757 & 2.113 & 2.042 \\
\hline $\mathrm{CCRb} \quad(\mathrm{Nb})$ & -0.224 & -0.266 & -0.183 & -0.058 & -0.083 \\
\hline CCRl (YF) & -0.017 & -0.068 & 0.033 & 0.182 & 0.153 \\
\hline CCR2 (e) & -3.287 & -3.203 & -3.370 & -3.628 & -3.576 \\
\hline CCR3 (E) & ---- & -0.045 & 0.058 & 0.211 & 0.181 \\
\hline CCR4（G） & -0.135 & -0.182 & -0.090 & 0.045 & 0.018 \\
\hline $\operatorname{CCRS}(\gamma)$ & -34.397 & -33.025 & -35.740 & -39.877 & -39.053 \\
\hline $\operatorname{ccR} 6(\lambda)$ & 0.436 & 0.366 & 0.504 & 0.711 & 0.670 \\
\hline $\operatorname{CCR} 7 \quad(\zeta)$ & 0.474 & 0.402 & 0.543 & 0.754 & 0.713 \\
\hline CCR8 (W) & 0.436 & 0.366 & 0.504 & 0.711 & 0.670 \\
\hline
\end{tabular}

Table 4

RANKING OF COMPLEMENTARITY-CONFLICT RATIOS

FROM "MOST COMPLEMENTARY" TO "MOST CONFLICTING"

\begin{tabular}{|c|c|c|c|c|c|c|c|c|c|c|c|c|}
\hline \multirow{3}{*}{$\begin{array}{c}\text { Time } \\
\text { Period }\end{array}$} & \multicolumn{6}{|c|}{$\begin{array}{c}\text { COMPLEMENTARY INDE PE NDE NT } \\
\text { VARIABLES } \\
\text { CCR }>0 \\
\end{array}$} & \multicolumn{6}{|c|}{$\begin{array}{c}\text { CONFLICTING INDEPENDENT } \\
\text { VARIABLES } \\
\text { CCR }<0\end{array}$} \\
\hline & \multirow{2}{*}{$\mathrm{C}$} & \multicolumn{2}{|c|}{$\begin{array}{c}\text { Most } \\
\text { Complementary }\end{array}$} & + & \multicolumn{2}{|c|}{$\begin{array}{c}\text { Least } \\
\text { Complementary }\end{array}$} & \multicolumn{3}{|c|}{$\begin{array}{c}\text { Least } \\
\text { Conflicting }\end{array}$} & & \multicolumn{2}{|c|}{$\begin{array}{c}\text { Most } \\
\text { Conflicting }\end{array}$} \\
\hline & & $\zeta$ & $(\lambda ; W)$ & & & & & YF & G & $\mathrm{Nb}$ & e & $\gamma$ \\
\hline $1967-70$ & $\mathrm{Na}$ & $\zeta$ & $(\lambda, W)$ & & & & $\varepsilon$ & Y F & G & $\mathrm{Nb}$ & e & $\gamma$ \\
\hline $1970-74$ & $\mathrm{Na}$ & $\zeta$ & $(\lambda, W)$ & $\varepsilon$ & YF & & & & G & $\mathrm{Nb}$ & e & $\gamma$ \\
\hline $1974-77$ & $\mathrm{~N} \mathrm{a}$ & $\zeta$ & $(\lambda, W)$ & $\varepsilon$ & YF & G & & & & $\mathrm{Nb}$ & e & $\gamma$ \\
\hline $1977-80$ & $\mathrm{Na}$ & $\zeta$ & $(\lambda, W)$ & $\varepsilon$ & YF & G & & & & $\mathrm{Nb}$ & $\mathrm{e}$ & $\gamma$ \\
\hline
\end{tabular}


Table 5

CCRT'S, THE PERCENTAGE CONTRIBUTION OF THE EXOGENOUS, POLICY/EXOGENOUS AND POLICY VARIABLES TO INDUCED GRONTH AND THE CCRT, AND THEIR EFFECTS ON REGIONAL INEQUALITY

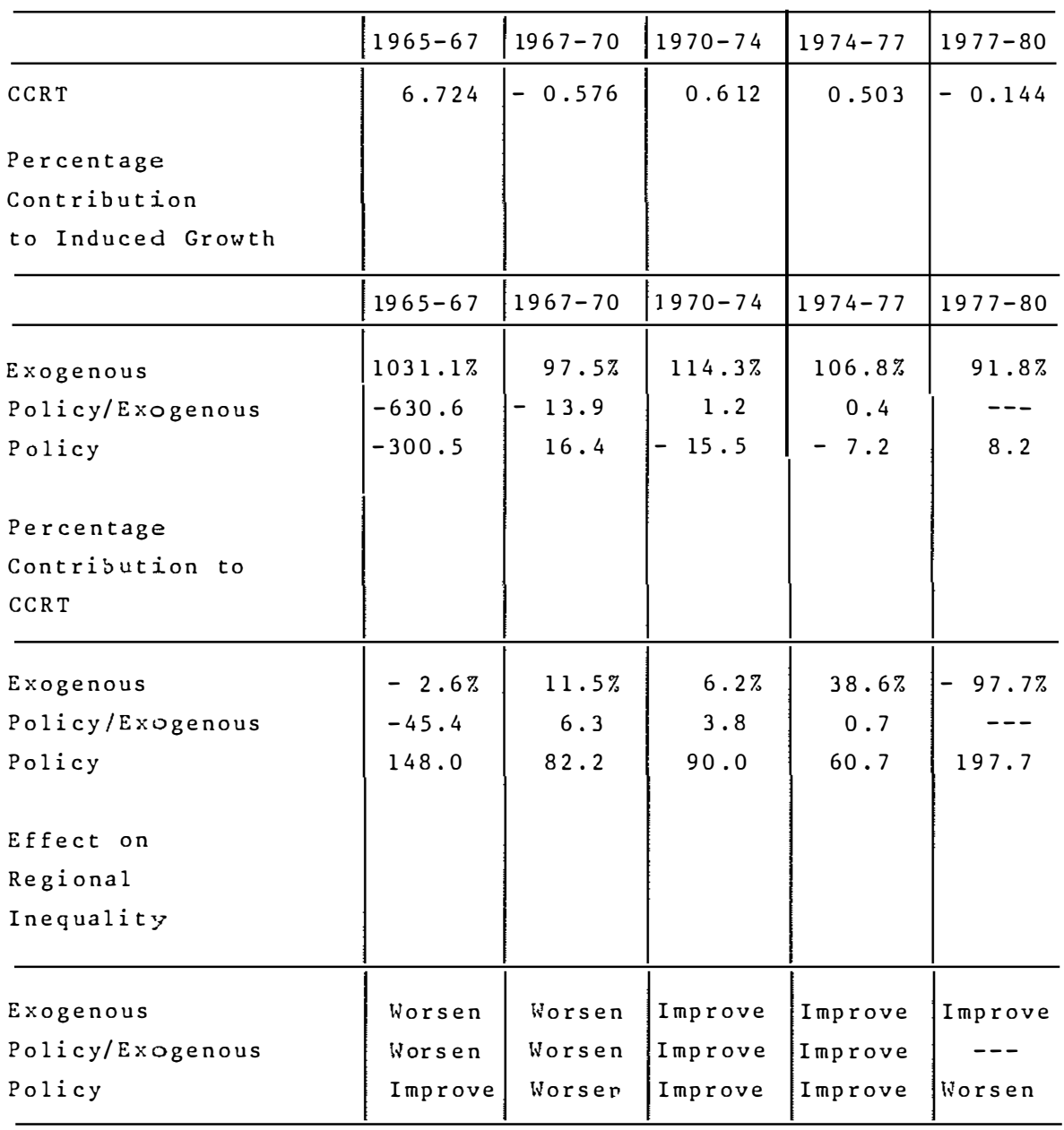


Table 6

PERCENTAGE CHANGE OF THE EXOGENOUS AND POLICY VARIABLES AND THEIR GROWTH RATE COEFFICIENTS

\begin{tabular}{|c|c|c|c|c|c|c|}
\hline \multicolumn{2}{|c|}{$\begin{array}{l}\text { Percentage } \\
\text { Change of }\end{array}$} & $1965-70$ & $1967-70$ & $1970-74$ & $1974-77$ & $1977-80$ \\
\hline \multicolumn{2}{|c|}{$\frac{\text { Exogenous }}{Y \mathrm{~F}}$} & $8.50 \%$ & $7.39 \%$ & $14.94 \%$ & $9.87 \%$ & $7.95 \%$ \\
\hline \multirow{4}{*}{ Policy } & e & $-16.48 \%$ & $9.60 \%$ & $-17.99 \%$ & $-9.15 \%$ & $9.81 \%$ \\
\hline & $\varepsilon$ & --- & 67.02 & 50.48 & 5.93 & --- \\
\hline & G & 15.00 & 27.77 & 1.54 & 69.92 & 12.11 \\
\hline & $\gamma$ & 52.33 & 16.65 & -39.29 & -11.98 & --- \\
\hline \multicolumn{7}{|c|}{ Growth Rate Coefficients* } \\
\hline \multicolumn{2}{|c|}{$\frac{\text { Exogenous }}{Y F}$} & 625.13 & 623.23 & 503.30 & 372.28 & 334.88 \\
\hline \multirow{4}{*}{ Policy } & e & 94.62 & 72.62 & 59.85 & 31.59 & 23.50 \\
\hline & $\varepsilon$ & --- & 0.82 & 1.03 & 1.00 & --- \\
\hline & G & 0.73 & 0.77 & 0.74 & 0.49 & 0.68 \\
\hline & $\gamma$ & -0.002 & -0. & -0.003 & -0.001 & $-\cdots$ \\
\hline
\end{tabular}

*The Growth Rate Coefficients are the indicated variables' coefficents in equation 8 .

SOURCE S :

Calculated from data in Fundação Getulio Vargas, Conjuntura, various issues; Officie of the President, Economic Report of the President, 1981; and Table 2 above. 


\section{NOTES}

1. The effect of relaxing these assumptions is merely to complicate the analysis presented below. The major conclusions and implications remain the same.

2. Although a variable's growth rate is technically different than the proportional change in that variable, the two terms will be used synomously in this paper.

3. It should be noted that inequality can worsen even though the regional income levels are increasing. This situation is analogous to the fact that the Gini coefficient for the personal income distribution can increase while the levels of personal income of all individuals are increasing.

4. The condition that $\mathrm{Ei}_{1}+\mathrm{Ej}_{2}<1$ is a sufficient condition for the model's stability. See Appendix I for proof and inter pretation of these conditions.

5. The Total or Aggregate Complementarity-Conflict ratio is deri ved by dividing equation 9 by equation 8 and simplifying.

6. For a review of this literature see Harber (1982a).

7. For example, see Haddad and Andrade (1974), Rebousas (1976), Baer and Geiger (1978), and Martin and Schuh (1978).

8. The model is a synthesis and extension of the models analyzed in Harber (1982a) and Harber (1982b). The parameter estimates preserited below are also drawn from these works.

9. See Appendix I f for the presentation of the structural equations and Harber (1982a) for a detailed discussion of Brazil's incentive programs.

10. The result that the pure policy variables had negative effects one growth in the 1965-67, 1970-74 and 1974-77 subperiods is primarily due to the effective revaluation of the real exchan ge rate despite the substantial nominal devaluations which occured. 


\section{REFERENCES}

1. Baer, W., and P.P. Geiger. "Industrialização, Urbanização e a Persistência das Desigualidades Regionais no Brasil", Dimen sóes do Desenvolvimento Brasileiro. Eds.: Werner Baer, Pe= dro Pinchas Geiger and Paulo Roberto Haddad. Rio de Janeiro: Editora Campus Ltda., 1978, pp. 65-150.

2. Haddad, P.R., and T.A. Andrade. "Política Fiscal e Desequilibrios Regionais", Estudos Econômic»s, 1974, 4, pp. 9-54.

3. Harber, R.P. The Impact of Fiscal Incentives on the Brazilian Northeast. Unpublished Ph.d. Dissertation, University of Illinois, 1982 .

4. Harber, R.P. "O Sistema de Incentivos Fiscais e o Nordeste:Uma Anälise Econometrica," Revista Economica do Nordeste, Vol.13, no. 4, Outubro/Dezembro 1982, pp. 705-742.

5. Martin, Marshall A., and G. Edward Schuh. "The Impact of Brazilian Trade Policies on the Regional Distribution of Income." Paper presented at the Symposium on Socio-economic Chan ge in Brazil, University of Wisconsin; Madison, Wisconsin $\bar{i}$ May $10-13,1978$.

6. Rebouças, Osmundo E. "Efeitos de Políticas Econômicas Sobre as Disparidades Entre o Nordeste e o Centro-Sul do Brasil: Um Modelo Multi-Setorial de Equilíbrio Geral," Estudos Económi cos, 1976,6 , pp. 83-112. 
APPENDIX I: STABILITY ANALYSIS OF THE BASIC TWO REGION MODEL

To analyze the satability of the model presented in sectionII, assum all the exogenous and policy variables are unchanging so that the model reduces to the following:

$$
\begin{aligned}
& Y a=E a(Y a, Y b)+M b(Y b)-M a(Y a)=F a(Y a, Y b) \\
& Y b=E b(Y b, Y a)+M a(Y a)-M b(Y b)=F b(Y b, Y a)
\end{aligned}
$$

where

$$
\begin{aligned}
& \mathrm{Fa} \mathrm{a}_{1}=\mathrm{Ea_{1 }}-\mathrm{Ma} \mathrm{a}^{\prime}<1 \\
& \mathrm{Fb}_{1}=\mathrm{Eb} \mathrm{b}_{1}-\mathrm{Mb}^{\prime}<1 \\
& \mathrm{Fa}_{2}=\mathrm{Ea}_{2}+\mathrm{Mb} \mathrm{b}^{\prime}>0 \\
& \mathrm{Fb}_{2}=\mathrm{Eb}_{2}+\mathrm{Ma}^{\mathrm{T}}>0
\end{aligned}
$$

or, in equilibrium

$$
\begin{aligned}
& Y a-F a(Y a, Y b)=0 \\
& Y b-F b(Y b, Y a)=0 .
\end{aligned}
$$

Using the standard interpretation of Keynesian product market equilibrium, treating Ya and Yb as production levels and Fa and Fb as total net purchases, then the disequilibrium adjustment proces ses are as follows:

i) For a given level of Ya, if Yb is such that Ya $>(<)$ Fa(Ya, Yb) then production exceeds (falls short of) purcheses so that stocks are accumulating (decumulating) in Region A and pro duction is decreased (increased); and

ii) For a given level of Yb, if Ya is such that Yb> (<) Fb(Yb,Ya), then production exceeds (falls s: ort of) purchases so that stocks are accumulating (decumulating) in Region $B$ and pro duction is decreased (increased).

The equilibrium conditions given above can the used define the combinations of Ya and Yb satisfying these conditions. Totally dif ferentiating the equilibrium conditions yields the following ex= pressions for the slopes of these equilibrium loci:

Region $A:\left.\frac{d Y a}{d Y b}\right|_{A}=\frac{F a_{2}}{I-F a_{1}}>0$

Region $B:\left.\frac{d Y_{a}}{d Y_{b}}\right|_{B}=\frac{1-F_{1}}{F_{2}}>0$. 
Figures A.1 and A.2 show the two possibilities for a nonneutral equilibrium of the model. In Figure A.l the slope of Region B's equilibrium locus (BB) is greater than the slope of Region A's equilibrium locus (AA) and the equilibrium is stable. In Figure A.2 the relationship between the slopes of the equilibrium loci is reversed and the equilibrium is unstable. Thus, it is clear that the necessary condition for the model's stability is

$$
\left.\frac{d Y a}{d Y b}\right|_{B}>\left.\frac{d Y a}{d Y b}\right|_{A}
$$

or

$$
\frac{1-\mathrm{Fb}}{\mathrm{Fb}_{2}}>\frac{\mathrm{Fa}_{2}}{1-\mathrm{Fa}_{1}}
$$

Substitution of the expressions for the partial derivatives of the Fi functions and manipulation of this expression shows that the mo del's stability guarantees that the denominator of the coefficients in equations 7,8 , and 9 are positive. It is also easily shown that a sufficient condition for stability is

$$
\mathrm{Ea}_{1}+\mathrm{Eb}_{2}<1 \text { and } \mathrm{Eb} \mathrm{b}_{1}+\mathrm{Ea}_{2}<1 \text {. }
$$

These conditions simply state that the change in non-trade, direct expenditures in both regions resulting from a change in either region's income is less than the initial change it income.

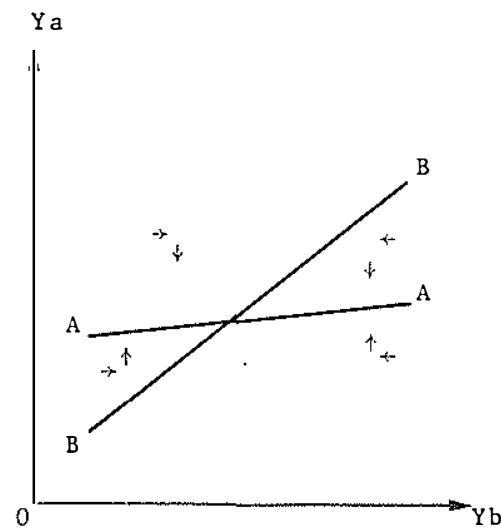

FIGURE A. 1 :

Stable Equilibrium in the Two Region Model

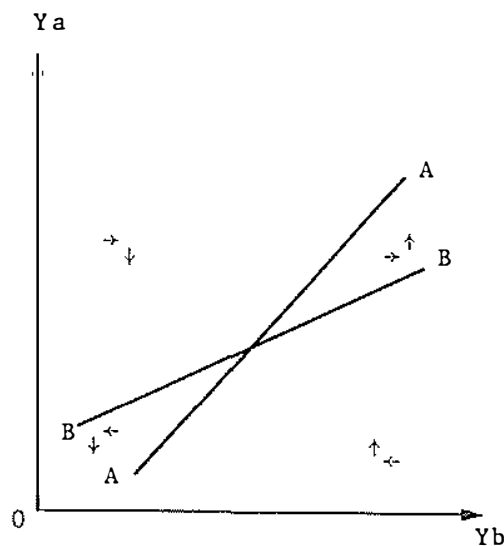

FIGURE A. 2:

Unstable Equilibrium in the Two Region Mode? 
APPENDIX II: THE UNDERLYING MODEL OF SECTION IV

The macro-model underlying the analysis of section IV is based upon the models developd in Harber (1982) and Harber (forthcoming), These works are designed to evaluate the effects of Brazil's fis cal incentive system on the Northeast region. All variables are in real terms. The structural equations for the two regions are the following:

Definitions of Disposable Income: $\mathrm{YDi}=\mathrm{Yi}-\mathrm{Ti}$

Consumption Functions: $\mathrm{Ci}=\mathrm{Ci}(\mathrm{YDi}), 0<\mathrm{Ci}^{\prime}<1$

Government Revenue Functions : $\mathrm{TGi}=\mathrm{TGi}(\mathrm{Yi}, \varepsilon), \mathrm{TGi}_{2}<0<\mathrm{TGi}{ }_{1}<1$

Incentive $\mathrm{Tax}$ Functions: $\mathrm{TI} i=\mathrm{TI}\left(\mathrm{Yi}^{\mathrm{i}}\right), 0<\mathrm{TI} \mathrm{T}^{\prime}<1$

Total Tax Functions: $\mathrm{Ti}=\mathrm{TGi}+\mathrm{TIi}=\mathrm{Ti}(\mathrm{Yi}, \varepsilon)$

Investment Functions: $I a=(1+\lambda) \zeta N a Z$

$$
I b=(1+\lambda)(1-\zeta) \mathrm{Nb} Z, 0<\zeta<1
$$

Government Expenditure Functions: $G a={ }_{\gamma} G, 0<\gamma<1$

$$
\mathrm{Gb}=(1-\gamma) \mathrm{G}
$$

Foreign Export Functions: $x i=x i(Y F, e, \varepsilon) ; x i_{1}, x i_{2}, x i_{3}>0$

Foreign Import Functions: $\mathrm{pi}=\mathrm{pi}\left(\mathrm{YDi}_{\mathrm{i}} \mathrm{e}\right), \mathrm{pi}_{1}>0, \mathrm{pi}_{2}</>0$

Regional Import Functions: $M i=M i(Y D i), M i{ }^{\prime}>0$

Regional Export/Import Functions: $x i=M j ; i, j=a, b ; i \neq j$

Avai lable Incentive Funds: $Z=W Z_{t-1}+T I a+T I b$

where

$\varepsilon=$ the degree of export subsidy granted through the tax syster;

$\zeta=$ Region A's share of the disbursed incentive funds;

$\gamma=$ Region A's share of total, exogenous government expendit $\underline{u}$ res (G);

$\lambda=$ the ratio of private (non-incentive-induced) investmentto incentive induced investment; 
e = the real exchange rate (domestic currency units per unit of foreign currency;

$\mathrm{Ni}=$ Region i's aggregate incentive-investment multiplier, $\mathrm{Ni}>0$;

$W=$ the fraction of incentive funds retained per time period, $0<W<1$; and

$I F=$ foreign (United States) income.

Aggregate regional expenditures are composed of the consumption, investment, government and net foreign export expenditures of each region. Thus

$$
\begin{aligned}
E i & =C i+I i+G i+x i-p i \\
& =E i(Y i, Y j, N i, Y F, e, \varepsilon, G, Y, \lambda, \zeta, W) .
\end{aligned}
$$

